\title{
Restaurar ¿es todavía posible?
}

"Restauración: La palabra y el hecho son modernos..."1 Así se expresaba Viollet - le - Duc, hace aproximadamente ciento treinta años, al inicio de la voz "Restauration" contenida en el "Dictionnaire raisonné de l'architecture française du XI au XVI siécle" (1854-1868). El hecho de la restauración para Viollet consistió en recuperar, o propiciar, la unidad orgánica perdida en muchos edificios, entre funcionalidad y estructura, entre arte y técnica -adaptando a un racionalismo constructivo, romántico en sus fines últimos, el método comparado aplicado por G. Couvier a las ciencias naturales-. A pesar de lo impecable de muchos de sus escritos teóricos 2 y lo acertado de sus primeras restauraciones, (por ejemplo la restauración de la Iglesia de la Madeleine en Vézelay), su teoría sobre el comportamiento estructural de la bóveda gótica y el carácter estructuralista de su concepto de estilo, le acarreó serias críticas entre los arqueólogos contemporáneos $^{3}$, poniendo en crisis epistemológica el concepto de restauración. Además, para muchos otros que se declararon seguidores del maestro francés, la restauración consistió simplemente en reinventar una unidad estilística, en el mejor de los casos no exenta de algún logro estético, pero la mayoría de las ocasiones injustificada y bajo la constante sospecha o anatema de falsedad histórica. Desde entonces la palabra y el hecho de la restauración cayeron bajo sospecha de vanidad humana, negligencia histórica y condición antinatura, oponiendo una actitud conservadora a la llamada escuela restauradora.

Hoy, en las postrimerías del siglo XX, cuando el término "restauración" tiene distinto significado al decimonónico, resulta extraño que se siga oponiendo conservar a res- taurar, como si se tratase de dos maneras excluyentes de entender la intervención en la arquitectura preexistente. Hasta el extremo, que en la actualidad, hablar de restauración vuelve a estar bajo sospecha y conservar se manifiesta, no sólo como lo más prudente, sino como la única posibilidad legítima.

Resulta además paradójico, que si la noción y acción de restauración heredadas del siglo XIX se condenaron fue por su total identificación con la "restauración en estilo", que conducía a falsedades históricas al renunciar a la utilización de la arquitectura del momento como hecho diferencial, mientras que en la actualidad se rechaza por todo lo contrario. Especialmente en España, tras un periodo que podemos llamar de restauraciones de autor, opiniones cada vez más extendidas recelan, o se manifiestan claramente contrarias a la eficacia de la arquitectura contemporánea para resolver la salvaguarda del patrimonio histórico, su identidad. Este es un tema que nos debe hacer reflexionar, aún más, cuando en ocasiones coinciden, al menos en apariencia, opiniones críticas con intenciones muy diferentes. Por un lado encontramos actitudes nostálgicas del pasado, con un concepto de la historia congelada por ciclos, mientras que en la otra orilla, otros, apostamos por entender la restauración como un arma cargada de futuro, pero, en la que la violencia estética o constructiva con el patrimonio no tiene sentido.

No debe ser ajeno a esta aparente contradición histórica, la evidente ambigüedad semántica de los términos protección, preservación, conservación, restauración, rehabilitación, repristinación, etc., que indudablemente añade 


\section{por Juan Francisco Noguera}

1. Interior de la Iglesia de la Madeleine en Vézelay, con las bóvedas restauradas por Viollet-le-Duc.

más confusión. Entre ellos, el binomio conservación restauración, y la rehabilitación, son los que más conflictos plantean. Estos términos han tenido diversas interpretaciones a lo largo del tiempo y todavía, en la actualidad, ven entremezclarse sus significados.

Propongo, pues, reflexionar acerca del sentido que, hoy en día, se puede dar a estas acciones, pues cabe preguntarse si es posible todavía, defender, con prudencia y un sentimiento de progreso, la restauración del patrimonio arquitectónico como una necesidad. ¿En qué términos convendría entender el concepto de restauración, sin que peligre la identidad del patrimonio restaurado? ¿Cuál puede ser la relación de la arquitectura moderna en su encuentro con la histórica? En fin, ¿Qué papel se le debe reservar en el futuro, en materia de conservación y restauración?

La restauración como proceso metodológico de conocimiento y puesta en valor

Hace veinte años el ICOMOS tomó la decisión de celebrar en Ravello un encuentro sobre terminología comparada relacionada con el patrimonio ${ }^{4}$. Sin embargo, a pesar del tiempo transcurrido, consideramos que aquellas definiciones, consensuadas con pretendida validez internacional, siguen siendo operativas. En la base de todo el sistema de conservación del patrimonio se encuentra la protección 5 del mismo, que, aunque puede entenderse en su sentido más amplio como cualquier acción destinada a la perpetuación del patrimonio, se ejerce principalmente con medidas legales, desde la declaración monumental hasta normativas de tipo urbanístico como, por ejemplo,

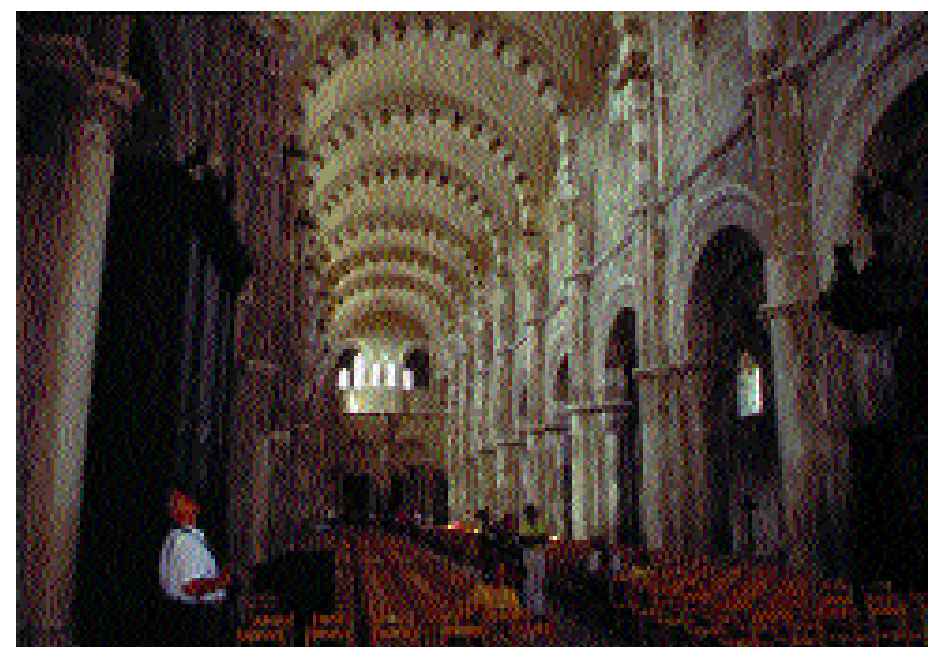

la eliminación del tráfico. Sin embargo, esta protección legal se muestra insuficiente en la mayoría de los casos, al necesitar el monumento acciones complementarias que, dentro de una protección integral activa, aseguren el reconocimiento y recuperación de todos sus valores, como el buen mantenimiento de los mismos. Precisamente, el reconocimiento, recuperación, mantenimiento y transmisión de los valores de una obra de arquitectura, constituyen la esencia de la restauración, siendo el Proyecto de restauración, junto con las acciones derivadas del mismo, el instrumento más eficaz para asegurar esta protección.

En el encuentro de Ravello, por restauración se entendió "el conjunto de operaciones técnico - científicas dirigidas a garantizar dentro del campo de una metodología crítico - estética la continuidad de una obra de arte"6. De esta definición se desprende que cualquier operación, consecuencia de una metodología de análisis e intervención, destinada a conservar, recuperar o potenciar valores históricos, artísticos, arquitectónicos, ambientales y sociales, de una obra de arquitectura, para su transmisión al futuro, entra dentro del campo de la restauración. La interpretación coincide con lo expuesto en la "Carta -italiana- de 1987 de la Conservación y Restauración” en la que se define la restauración como "cualquier intervención que, respetando los principios de conservación, y sobre la base de todo tipo de indagaciones cognoscitivas previas, se dirija a restituir al objeto, en los límites de lo posible, la relativa legibilidad y, donde sea posible, el uso"7.

La restauración no tiene por qué responder, (aunque en 


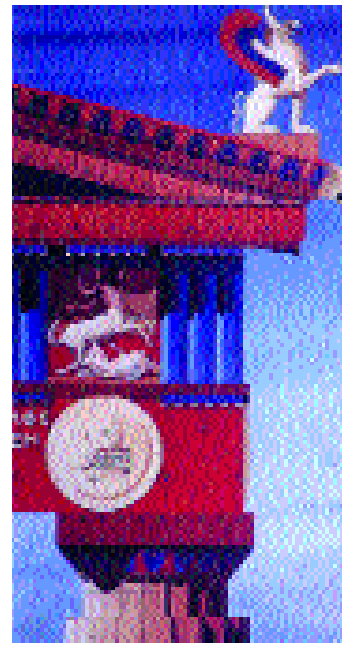

determinado caso pueda hacerlo), al significado decimonónico de reconstrucción en estilo, ni necesariamente a operaciones que vayan más allá de las puramente preservativas o conservadoras. Las operaciones de repristinación, consolidación, preservación, reintegración, mantenimiento, etc. deben ser entendidas como interpretación particular, en cada caso, del concepto amplio de la restauración, en tanto que exigen, y se justifican desde el conocimiento previo, profundo y crítico, del monumento, a partir de la aplicación de una metodología de investigación y acción. La finalidad de la restauración debe ser doble: reforzar el conocimiento del monumento y consolidar sus valores. Con demasiada frecuencia se olvida lo primero, fracasándose en lo segundo.

Hacia una metodología crítica y empírica, o, la "teoría del caso por caso".

Uno de los problemas históricos -no superado totalmente-, fue la restauración basada en el método comparado, con un concepto estructuralista de la noción de estilo, que, aplicando generalidades, olvidó en muchos casos la singularidad del monumento poniendo en peligro su propia identidad.

No podemos establecer pautas ni teorías generales, pues es el monumento el que ha de dictar su futuro. La restauración es en casos preciosos una novela de intriga y misterio que no se desentraña sin un gran esfuerzo, método, paciencia, y una colaboración interdisciplinar en la investigación del propio edificio. Las piedras y los morteros, las juntas y las trabas, son frágiles pero hablan,
2. Restitución gráfica del Partenón según Loviot (1879). La restauración debe detenerse donde comienzan las hipótesis. susurran si se les sabe escuchar. Es el edificio el que mejor guarda su memoria. El secreto radica en hacer hablar al monumento; el acierto está en saber escuchar: no solamente al edificio, su ambiente, bienes o documentos, sino a quienes tienen cosas que decir acerca del mismo, entre los que se cuenta, frecuentemente olvidados, el saber y el sentir popular 8 .

En definitiva, defendemos la restauración como un proceso metodológico empírico y crítico, de conocimiento que conduce a, y, a su vez, es facilitado por una puesta en valor del monumento para su transmisión al futuro. La restauración exige la conservación de la materia y una recuperación y actualización del máximo de valores históricos, sociales, artísticos, arquitectónicos y constructivos, en un proceso interactivo entre reconocimiento y revalorización. En la fase de análisis, las técnicas no destructivas, -complementarias de las tradicionales-, deben desarrollarse y perfeccionarse, para desempeñar un papel cada vez más relevante en ese reconocimiento. El empleo de sistemas constructivos coherentes, la publicación y difusión del conocimiento obtenido y un plan de seguimiento, son partes esenciales de su valoración y protección.

La restauración como conservación de la materia original y recuperación de valores tradicionales.

La restauración de la obra de arquitectura, entendida como la del conjunto de su materia y valores monumentales, presenta sus límites dictados por las preexistencias y el rigor en el conocimiento. Por lo cual, aún admitiendo que la recuperación de algunos de estos valores pue- 
3. La torre de las Damas en La Alhambra, Granada (foto 1995). La intervención realizada por Torres Balbás, considerada conservadora, constituyó una auténtica restauración del monumento.

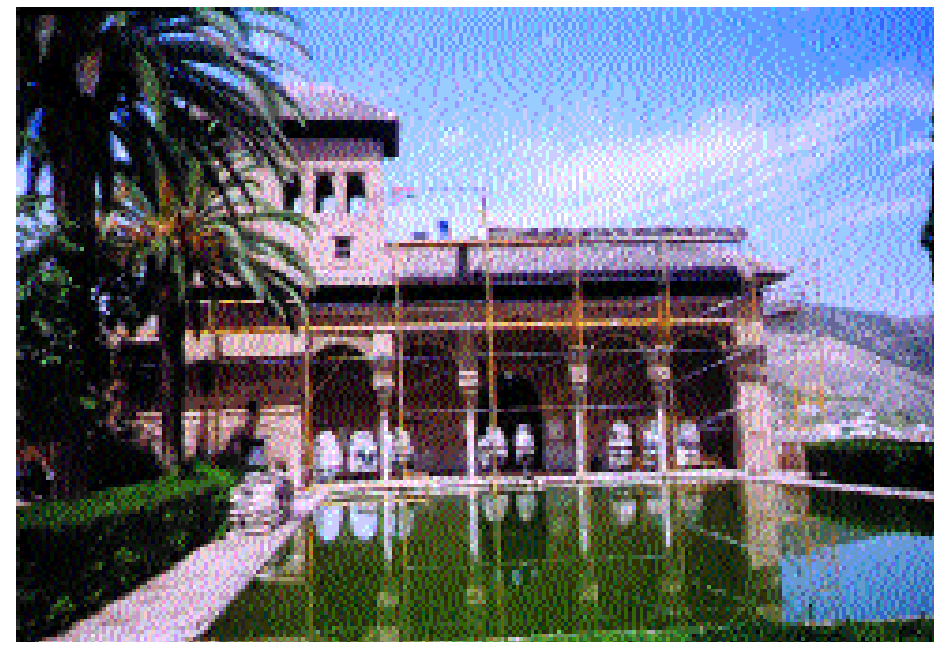

figuradoras del monumento-, se entiende como acción limitada, esencialmente, a la restauración de la materia existente para garantizar la salvaguarda de la identidad y autenticidad de la obra de arquitectura, desde la defensa del principio de "mínima intervención”; o bien, desde la prudencia que establezca un orden de prioridad de acciones, ante el desbordante problema de un patrimonio ingente ${ }^{11}$. (Sin embargo, esta actitud, no debería ser manipulada para enmascarar recortes políticos presupuestarios, justificados como rechazo a supermillonarias intervenciones anteriores, para después seguir haciendo un uso ideológico-político de operaciones de restauración claramente propagandísticas).

En cualquier caso, no debemos ignorar que existe un patrimonio que es preciso estudiar y cuyos valores en vía de extinción deben, inevitablemente, restaurarse, como se ha demostrado en bastantes ocasiones-, si queremos recuperar su eficacia histórico-arquitectónica perdida, antes de que sea demasiado tarde. La posición conservadora es aceptable como actitud ética, pero no debe convertirse en axiomática.

El axioma, enunciado por Cesare Brandi12, que afirma que "se restaura sólo la materia de la obra de arte", al ser aplicado a la arquitectura, ha dado lugar, en ocasiones, a planteamientos e intervenciones radicales y antagónicos. Así, nos encontramos con actitudes "preservadoras" que condenan al monumento, despojado de su funcionalidad y valores espaciales, a una existencia en ruina, en la que el valor de la acción del tiempo o de antigüedad13 se presenta como el único a conservar. 


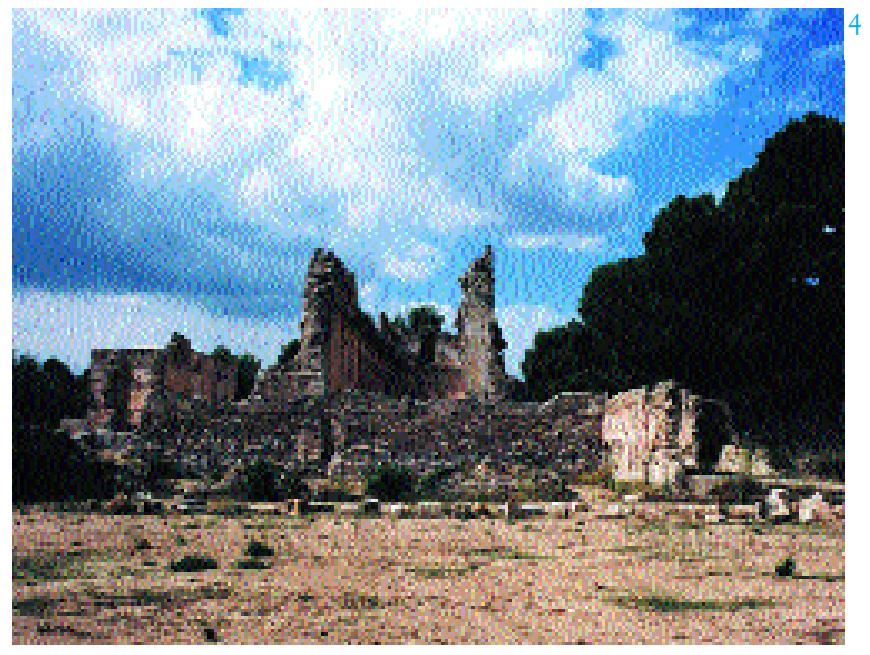

Mientras, en el otro extremo, con una confianza ciega en la rehabilitación a partir de la concepción arquitectónica y construcción modernas, se pierde, en ocasiones, la oportunidad de recuperar los valores espaciales y constructivos tradicionales propios del monumento, conservando, eso sí, la materia como un trofeo histórico. La manera de encontrar un punto de equilibrio, radica, en situar la cuestión de la funcionalidad en su justo sitio, partiendo de una noción amplia de la restauración aunque adecuada a cada caso.

\section{El uso como fin o como medio}

La rehabilitación, -término que parece tomado de la medicina terapéutica-, ha entrado a formar parte de nuestro vocabulario más reciente y más utilizado, introduciendo el peligro de una cierta perversión en su empleo y aplicación. En su sentido más estricto la rehabilitación se relaciona con la recuperación "funcional" de un miembro o de un conjunto. En la anteposición de la funcionalidad a la conservación de la materialidad, o a la restauración de los "valores monumentales", reside el peligro de su perversión al ser aplicado a edificios que requieren precisamente anteponer la restauración de sus valores patrimoniales culturales, y en los que la rehabilitación funcional puede ser un medio pero no el fin.

A partir de estos conceptos, se pueden clasificar los proyectos sobre el patrimonio en dos grandes apartados según su finalidad: Proyectos de restauración y proyectos de rehabilitación. La clasificación debe servir como estrategia en la que se defina el principal fin o prioridad

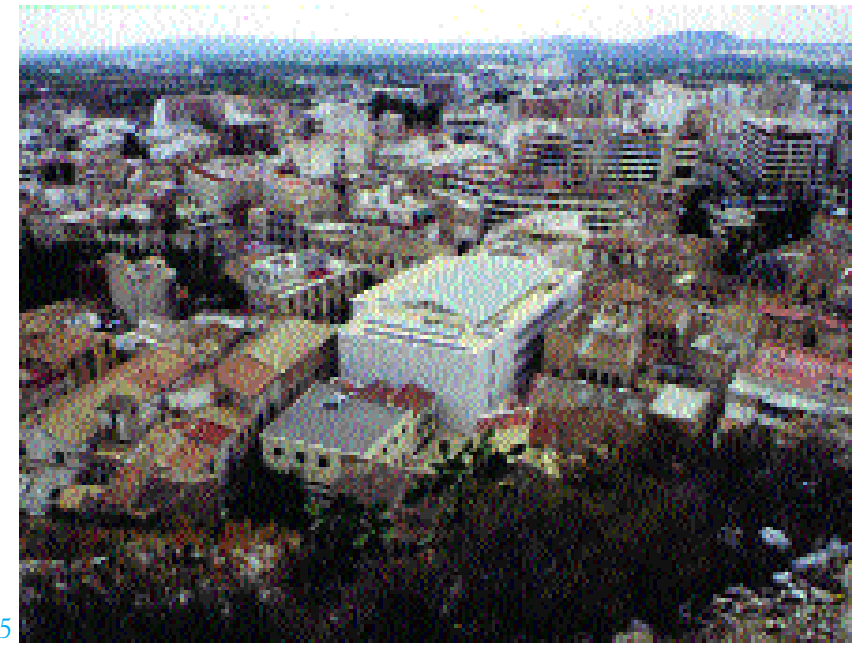

de la intervención. Los resultados deben responder al tipo de encargo, ya que, frecuentemente, los valores culturales históricos y el valor de uso entran en conflicto, sacrificándose, en demasiadas ocasiones, aquéllos a los funcionales.

En la actualidad, nadie duda de que la mejor manera, la única, de conservar un edificio, es utilizarlo. Sabemos que el único patrimonio histórico que sobrevivió hasta el s.XIX fue aquél al que se le dotó de algún uso. Nos consta que si muchos edificios, privados o públicos, de valor local histórico, se han salvado en las dos últimas décadas ha sido gracias a operaciones de rehabilitación, -aunque en ocasiones con una sensible pérdida de sus valores-. El problema, no obstante, lo constituye el conjunto de edificios de indiscutible valor monumental, en los que, cegados por la ilusión rehabilitadora y con un desconocimiento de lo que comportan las necesidades de sofisticados requerimientos funcionales o normativas insoslayables, se han puesto al borde de la desfiguración y la pérdida por usos inadecuados. ¿Qué hacer, entonces, para que el uso sea auténtica tabla de salvación?. Es muy fácil en teoría pero difícil en la práctica. Lo dijo G. Giovannoni y lo han repetido muchos después de él: la necesidad de coherencia funcional ha aparecido manifestada en muchas Cartas de Restauración. En la Carta de Atenas y en la Carta del Restauro italiana, ambas de 1931, se recogía, entre sus objetivos primeros, "conservar o devolver al monumento sus funciones", y el artículo $4^{\circ}$ de la última propone usos que "no produzcan alteraciones esenciales". La Carta de Venecia de 1964, en su 
4. La Cartuja de Valdecristo, Altura. Valencia. Es evidente la necesidad de priorizar las acciones ante el desbordante problema de un patrimonio ingente. Pero, no debe ignorarse la necesidad de su estudio y restauración si se quiere recuperar su eficacia histórico-arquitectónica perdida.

5. La Biblioteca Nacional de Orihuela, obra reciente de A. Campo Baeza, ha sustituido al palacio de Pinohermoso, cuya fachada, incluso, fue derribada finalmente, ante la supuesta presión de una funcionalidad, sirviendo sus restos de ornamento postmoderno.

6. Arco de Tito en Roma. Restaurado por R. Stern y G. Valadier.

7. Coliseo romano. Restauración de G. Valadier.
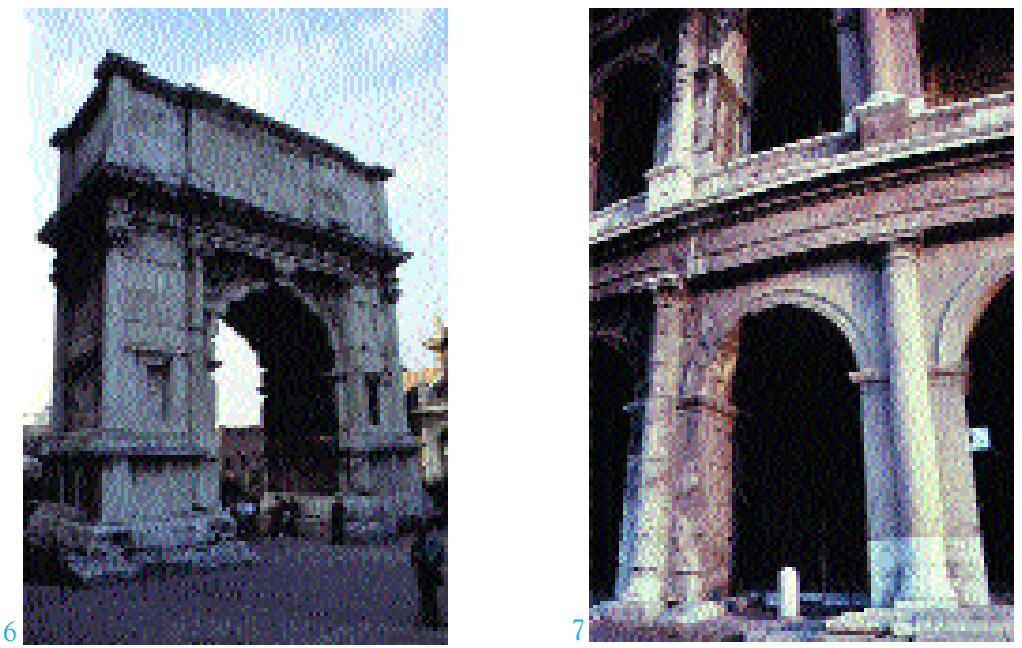

art. $5^{\circ}$ dice: "La conservación de los monumentos se asegura siempre con la dedicación de éstos a una función útil a la sociedad; esta dedicación es, pues, deseable, pero no puede ni debe alterar la disposición o el decoro de los edificios. Dentro de estos límites, se deben concebir y autorizar todos los arreglos exigidos por la evolución de los usos y las costumbres."

La restauración exige dotar a cualquier monumento de una función útil a la sociedad para su conservación, aunque sea, y no es poco, hacerlos visitables. En otros edificios, la actualización de su función o usos, aunque quede dentro de los límites a los que se refiere la Carta de Venecia, supone ciertas transformaciones que, al responder al espíritu del momento histórico de la restauración, pueden generar problemas de identidad con el monumento original.

\section{"Identidad - autenticidad" como condición ética de la restauración.}

El deterioro de la materia, la remodelación de los usos, la recuperación de los valores arquitectónicos, la actualización de la condición histórica, conlleva, consigo, desde operaciones de intervención en la propia materia histórica, hasta posibles complementos o ampliaciones, que, al alterar determinados aspectos y valores del monumento, plantean la necesidad de recuperar la identidad del mismo y preservar la autenticidad de las partes originales para evitar la posibilidad de engaño.

Identidad y autenticidad, han sido razones claves para la repristinación de monumentos, establecer criterios que seguir en su conservación y restauración, o justificar la de-restauración moderna. La autenticidad, "espina dorsal" de la Carta de Venecia, ha sido ampliamente debatida, especialmente en los últimos años, desde El Congreso Internacional de la Unesco sobre la Conservación de la piedra (París, 1993), el Coloquio de Nápoles, 1994, hasta la Carta de Nara, en 1994, sobre la Autenticidad. Estos conceptos no son tanto un valor sino una condición inherente a la consideración de patrimonio.

La identidad, concepto que según Gian Franco Borsi14 comprende el de autenticidad, debe ser entendida como sinónimo de "individualidad", referida a lo que un monumento tiene de singularidad, en cuanto a su propio ser como obra de arte, a su condición histórica y a su inserción en un contexto. La identidad del patrimonio es una “identidad histórica"; es el producto de su historia, y es un valor esencial, de la misma manera que la identidad del indivíduo o de un pueblo es su valor principal. Borsi la considera como el producto final de la "autenticidad de valores".

El concepto de autenticidad ha marcado toda una época de la restauración moderna desde Camilo Boito hasta el presente, entendiendo lo auténtico como lo original. Camilo Boito quiso ver en la restauración del Arco de Tito por Stern y Valadier, y en la restauración, por éste último, del Coliseo romano, los paradigmas de la restauración respetuosa con la identidad de las partes originales, al diferenciar el material y suprimir molduras en los añadidos. En su normativa de ocho puntos, introdujo además la diferenciación de estilo, más como una reitera- 

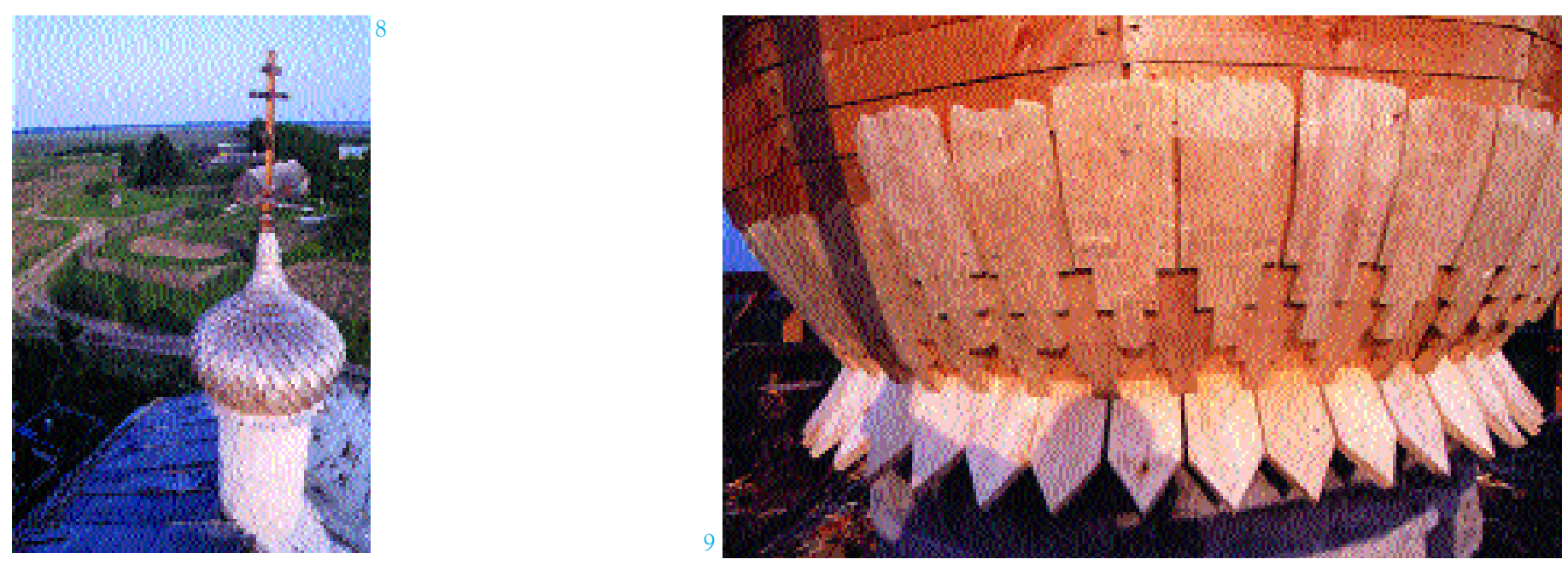

ción, que como una cuestión de expresión histórica del tiempo de la restauración. Tal vez por esta razón, creyendo ingenuamente lo de la neutralidad de las partes añadidas, se descuidó el aspecto artístico de muchas intervenciones posteriores. Hoy, tan auténticas son las partes originales romanas, como las añadidas por Valadier.

En la Carta de Venecia, la autenticidad se planteó como condición para la monumentalidad, desde el primer párrafo del preámbulo: "La humanidad... aspira a transmitir las obras monumentales con toda la riqueza de su autenticidad"15. Los artículos 9 y 12, insisten en este concepto. El artículo 9 hace referencia al "respeto a los elementos antiguos y las partes auténticas" y la necesidad de reconocer los complementos como obra de nuestro tiempo; y en el artículo 12 se insiste en "la distinción armónica de los elementos destinados a reemplazar las partes que falten".

La cuestión que sigue debatiéndose sobre la autenticidad, -no zanjada en la Carta de Venecia-, radica en la posibilidad de considerar separadamente el objeto del mensaje o valores, y distinguir, como plantea Raymond Lemaire ${ }^{16}$, una autenticidad histórica de una autenticidad formal. En estas cuestiones, el conocimiento del pensamiento filosófico de otras civilizaciones diferentes de la europea, como las orientales, provoca que la identificación de "autenticidad" con "original" no se pueda considerar universal y adquiera una mayor complejidad. Los valores, sobre los que aplicar estos conceptos, deben ser concebidos en su contexto social y cultural, no según modelos universales.
Esta separación entre "autenticidad histórica" y "autenticidad formal", no solo abre la posibilidad de una consideración de la noción de autenticidad más compleja, sino, lo que es más importante, tiene definitivas consecuencias en el concepto epistemológico de restauración. En efecto, aunque sometida a la individualidad de cada caso, desde la óptica expuesta, la restauración, como reintegración, se plantea, (como se expuso al principio), como una recuperación de valores, del mensaje, construcción y forma, pero no tanto de la materia original, que una vez perdida, es imposible devolver al monumento. Este enfoque, abre paso a la restauración con una materia diversa de la original, aunque como se expondrá más adelante, en coherencia con la forma, la construcción y la total materialidad del monumento, en un respeto máximo a su identidad. Materia puesta al servicio de la restauración de valores, como por ejemplo, el espacio, la forma, o la irisación conseguida con bellas vidrieras. La autenticidad no es un valor absoluto. El mismo concepto no se puede aplicar a una escultura, a un jardín histórico, a una fábrica de sillares, a un paisaje natural, a un centro histórico. Además, siempre deberemos tener en cuenta las variaciones de culturas, e incluso, de civilizaciones. J. L. Luxen, lo expuso muy claramente: “¿Porqué buscar un valor universal? ¿El verdadero valor universal no es precisamente el pluralismo? En sus últimas reflexiones Karl Popper nos pone en guardia contra los grandes sistemas fundados sobre valores absolutos. ¿Porqué no aceptar diversas acepciones de la autenticidad, según las culturas, según los diferentes 
8 y 9. La autenticidad no es un valor absoluto, depende de las culturas: restauración, renovando el material y manteniendo la forma y sistema constructivo en Stary Ladoga (Rusia).

10. Medina de Rioseco. Interior de la Iglesia de la Santa Cruz restaurada con gran sensibilidad por J. Ignacio Limazasoro.

11 y 12. Restauración del Palau de la Música. Barcelona. Tusquets, Díaz y Asociados.
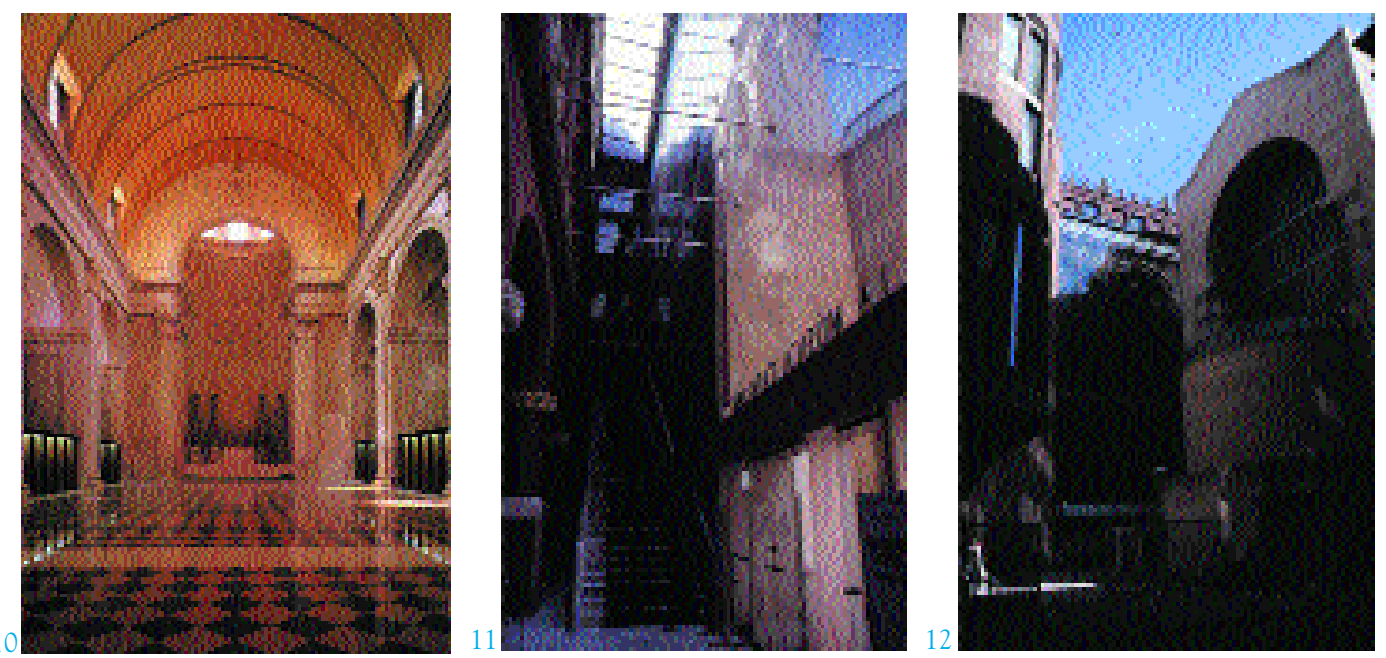

bienes?"17. El rigor científico y la exigencia ética, son las condiciones que constituyen el verdadero corazón de la autenticidad, debiendo guiar las reflexiones críticas. La autenticidad debe aplicarse especialmente a las fuentes de información. En éstas, y en la fidelidad de la restauración con las mismas, es donde reside el verdadero sentido de la autenticidad.

Coherencia estética y constructiva como valores opuestos al contraste y la heterogeneidad.

Sin olvidar el respeto a la sustantividad de cada caso particular, deseo romper una lanza a favor de una mayor consideración de la armonía estética y compositiva, de la recuperación de las técnicas constructivas tradicionales y de la coherencia constructiva. Armonía no supone reconstrucción mimética, ni destrucción de la variedad estratigráfica estilística de un monumento, ni renuncia a la creatividad. Coherencia constructiva significa homogeneidad en los comportamientos estructurales, frente a la heterogeneidad de la arquitectura actual, pero no uniformidad.

La restauración es, ante todo, como se ha defendido en estas páginas, un proceso de clarificación de valores. Y es indudable, que el conocimiento histórico, la valoración artística y las preferencias estéticas de una época influyen en dicha clarificación, y, por consiguiente, en los resultados de la restauración. Aloïs Riegl18 lo explicaba con el concepto de "kunstwollen" o "voluntad artística", -o estética-. Hoy en día, determinados valores abstractos artísticos y una estética del contraste, (confrontación más que contraste de opuestos), y del exhibicionismo constructivo y tecnológico, están transformando, a veces radicalmente, nuestros monumentos. El énfasis que hoy ponemos en los aspectos tipológicos, frente a la atención prestada en el pasado en los valores espaciales y ornamentales, compositivos y constructivos, ha conducido a una valoración ecléctica en la que la arquitectura actual se sitúa, cuanto menos, en un plano de igualdad con los estilos del pasado en la definición del espacio tipológico histórico.

Es correcto responder con el espíritu más avanzado de cada época. Según Cesare Brandi la restauración debe dar fe de los tres momentos históricos del monumento: de la época en que se construyó, del tiempo transcurrido y del momento de la restauración. Nadie debe dudar de la legitimidad de la arquitectura actual para representarnos. El problema comienza a surgir cuando ésta arrebata el protagonismo a la arquitectura del pasado, en su propio terreno. Algo comienza a fallar cuando, llevados por una estética actual de la confrontación, los excesos, el exhibicionismo y la fragmentación, el edificio, lejos de recuperar la armonía de sus proporciones, la serenidad de sus espacios históricos, lo genuino de su identidad, se convierte en una suma de restos y fragmentos, a los que, paradójicamente, se les ha arrebatado su anterior condición de ruina.

Por otra parte, estamos abocados a una arquitectura heterogénea de múltiples componentes y materiales, con interacciones difíciles de controlar. Con excesiva facilidad se sigue recurriendo al hierro, al cemento, al hormigón 


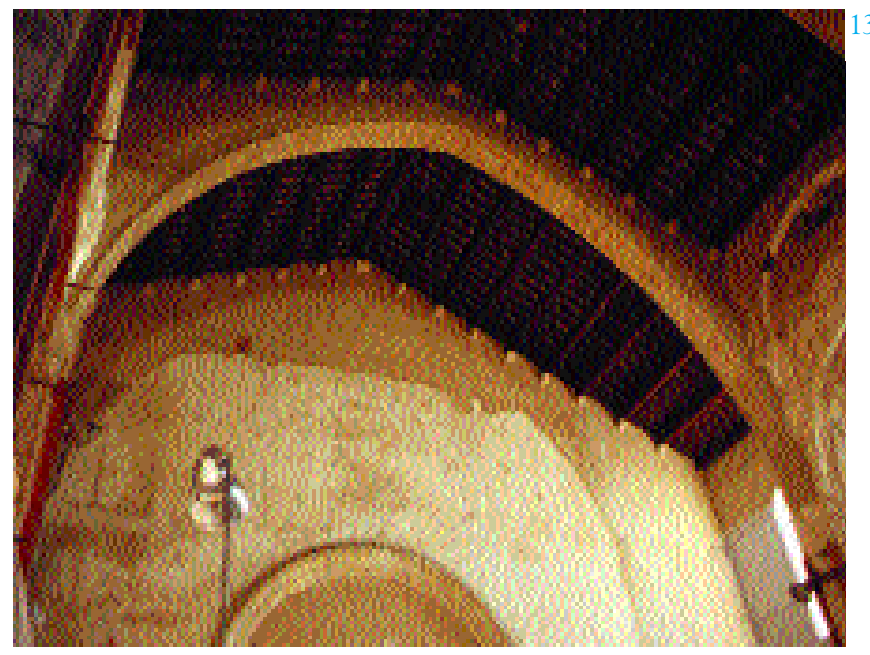

armado y a nuevos materiales, cuya eficacia en materia de restauración, es, en demasiadas ocasiones, por lo menos, dudosa ${ }^{19}$. Posiblemente, sea consecuencia del desconocimiento de las posibilidades de la albañilería, la cantería, los revestimientos, etc., como arte de construir con materiales como el ladrillo, la piedra, la cal o la tierra.

Con demasiada frecuencia mezclamos materiales, menospreciando las posibilidades de una construcción más coherente y, en definitiva, más armónica. Encontramos en la Carta italiana de 1987, recomendaciones muy claras para adoptar "las técnicas y los materiales tradicionales, que son más homogéneos con las obras que hay que salvaguardar" 20. Hace años clamamos por salvar el patrimonio, procuremos ahora que no se salgan con la suya quienes acusan a la arquitectura actual y a las restauraciones recientes, de encarnar el papel de ángel exterminador.

Nadie deduzca de estas palabras una actitud congeladora del patrimonio, sino una llamada a la reconciliación con el mismo que sólo puede lograrse partiendo del máximo respeto al monumento y desde la auténtica creatividad en el interior de la disciplina arquitectónica, en donde el proyecto y la obra, con ayuda de una metodología y una ética, deben contribuir a una mejor protección de nuestro patrimonio.

En España, la última década ha sido, a pesar de los excesos, la más brillante de la centuria, sin parangón en el encuentro entre arquitectura pensada para el futuro y la restauración del pasado. sin embargo, en la actualidad, corremos el riesgo de una recesión en los próximos años

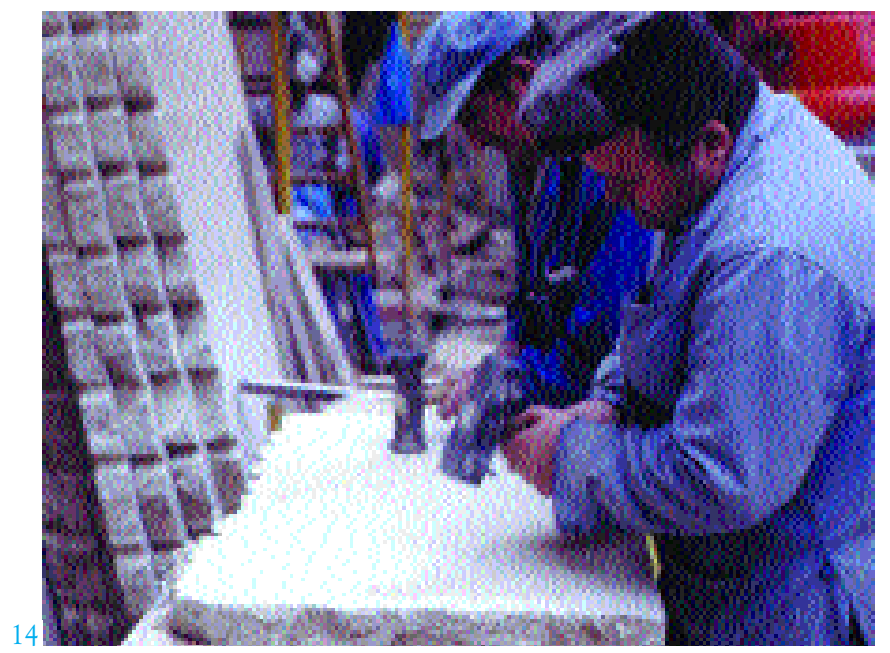

y el peligro de resucitar la vieja escisión entre memoria y modernidad. Para que esto no suceda debemos afrontar el reto de continuar con la labor emprendida, corrigiendo errores y explotando los aciertos, a partir de una reflexión sobre la experiencia acumulada. Reflexión crítica, profunda, abierta y continuada que conduzca a una creciente sensibilidad hacia el patrimonio histórico sin renunciar a la creatividad propia de nuestra época.

Notas:

1. Viollet-le-Duc: Voz "RESTAURATION, s.f. Le mot et la chose sont modernes. Restaurer un édifice, ce nést pas l'entretenir, le réparer ou le refaire, cést le rétablir dans un état complet qui peut n'avoir jamais existé à un moment donné." "Dictionnaire raisonné de l'architecture française" Paris V. A. Morel Cie, éditeurs. (1854-1868). t.VIII, pp. 14--34.

2. Ver: J. Fco Noguera: "Una lección de arquitectura: el artículo RESTAURATION del Diccionario de Viollet-le-Duc" Departamento de Composición Arquitectónica. SPUPV-89.214, 1989. La definición mencionada, expuesta al principio de la voz Restauración, contiene la afirmación, probablemente más desafortunada que puede hallarse entre los escritos de Viollet-le-Duc, incluídas las 21 páginas de este artículo, que constituyen una auténtica lección de restauración y arquitectura.

3. Sobre la relación de Viollet-le-Duc con la arqueología contemporánea ver: Pedro L. Gallego Fernández: "Vollet-le-Duc: La restauración arquitectónica y el racionalismo arqueológico fin de siglo" en RESTAURACIÓN ARQUITECTÓNICA. U. de Valladolid.

4. Ravello, abril de 1976. Ver Restauro n ${ }^{\circ} 32,1977$.

5. "Proteger: Acción jurídica para proteger de la eventualidad de daño, a objetos o bienes colectivos, que sin ésto estarían expuestos al riesgo de degradación y eventualmente extinción". Restauro $\mathrm{n}^{\circ} 32$.

6. Esta definición se corresponde con la dada por Cesare Brandi en "Teoria del restauro": "Il restauro constituisce il momento metodologico del riconoscimento dell'opera d'arte, nella sua consistenza fisica e nella sua duplice plarità estetica e storica, in vista della sua trasmissione al futuro." En castellano ver: C. Brandi: Teoría de la restauración. Alianza Forma 1988.

7. "Carta de 1987 de la Conservación y Restauración de los objetos de arte y cultura" editada por el Colegio de arquitectos de Málaga 1990, art. 2.

8. Ver, Juan Fco. Noguera "Bases para un debate en torno al Patrimonio arquitectónico", en Tribuna de la Construcción n ${ }^{\circ}$ 27, 1995, artículo referido a la Comunidad Valenciana. 
13 y 14. Restauración de las cubiertas de la iglesia de San Francisco de Xàtiva. 1982. Gisbert, Noguera y Otegui.

15 y 16. Intervención en la iglesia de San Francisco de Baeza. Con excesiva facilidad se sigue recurriendo al hierro, al hormigón armado y al contraste, con un resultado estético y constructivo, en demasiadas ocasiones, negativo.

17 y 18. Delegación del Colegio Oficial de Arquitectos en Huelva.
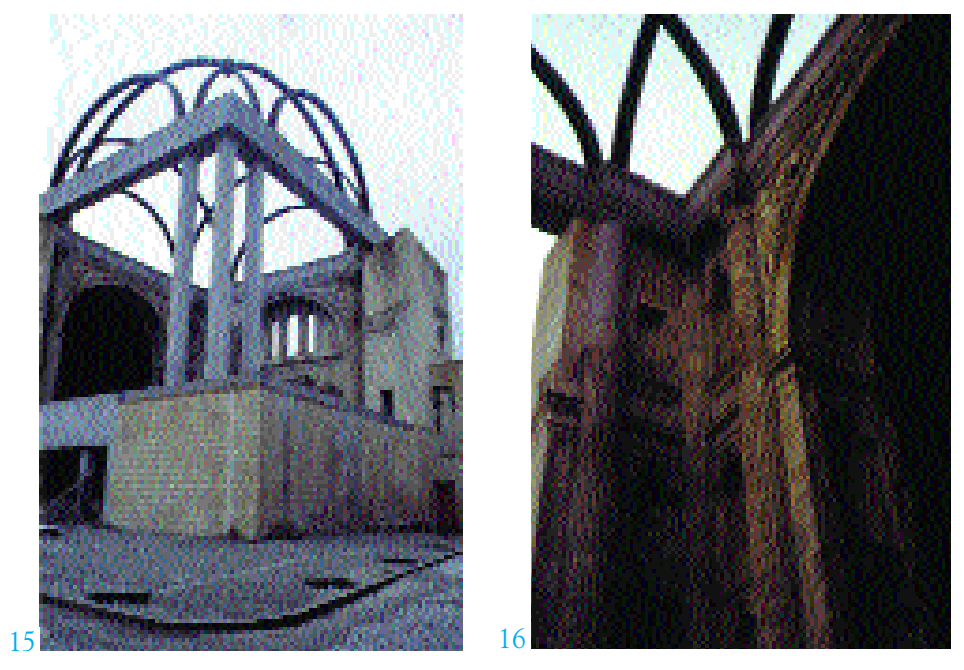

9. Materia y materialidad se utilizan con un significado complementario: se usa el primer término para designar la materia física propiamente dicha con la que está hecha la obra de arquitectura. Mientras que el vocablo materialidad se utiliza con un sentido más amplio, designando el conjunto de significados arquitectónicos no solo materiales sino también abstractos, como el espacio, la composición, la escala, la luz, etc.

10. En Ravello, se definieron:

Mantenimiento: "El conjunto de operaciones necesarias para mantener en perfectas condiciones o en estado de conservación un edificio o una construcción de cualquier tipo".

Preservar: "operación a realizar para garantizar la sobrevivencia contra la incidencia del ambiente o del tiempo".

En la Carta italiana de 1987, la conservación se definió como "el conjunto de actuaciones de prevención y salvaguarda referidos a asegurar una duración pretendidamente ilimitada a la configuración material del objeto considerado.

11. G. Giovannoni al establecer cinco tipos de intervención, establecía un orden de prioridades: "consolidación, recomposición (anastilosis), liberación, complementos e innovaciones". Ver: Juan Fco. Noguera: "Teorías de intervención en el patrimonio arquitectónico. Origen y desarrollo de las primeras propuestas normativas". Arquimur n ${ }^{\circ}$ 5-6, 1988.

12. C. Brandi: "Teoría de la restauración", p. 16.

13. Para una reflexión sobre los valores de los monumentos, incluído el de antigüedad, ver: Aloïs Riegl: "El culto moderno a los monumentos". Visor Distribuciones, S.A., 1987. Título original: "Der moderne Denkmalkultus. Sein Wesen und seine Entstehung", Viena 1903.

14. Gianfranco Borsi: "Apertura dei lavori” en Restauro n ${ }^{\circ}$ 130. 1994

15. Carta de Venecia, Mayo de 1964. Preámbulo: "La humanidad, que cada día toma conciencia de la unidad de los valores humanos, la considera como un patrimonio común, y pensando en las generaciones futuras, se reconoce solidariamente responsable de su conservación. Ella aspira a transmitirlas con toda la riqueza de su autenticidad".

16. Raymond Lemaire: "Authenticité et patrimoine monumental" en Restauro ${ }^{\circ} 129 / 1994$.

17. Jean Louis Luxen: "Messaggio". Restauro n 130.

18. Aloïs Riegl: "El culto moderno a los monumentos". Opus cit.

19. Ver la Carta italiana de 1987 de la Conservación y Restauración, art. 7 d).

20. Carta italiana de 1987 de la Conservación y Restauración, Anexo B Instrucciones para la conservación, mantenimiento y restauración de las obras de interés arquitectónico.
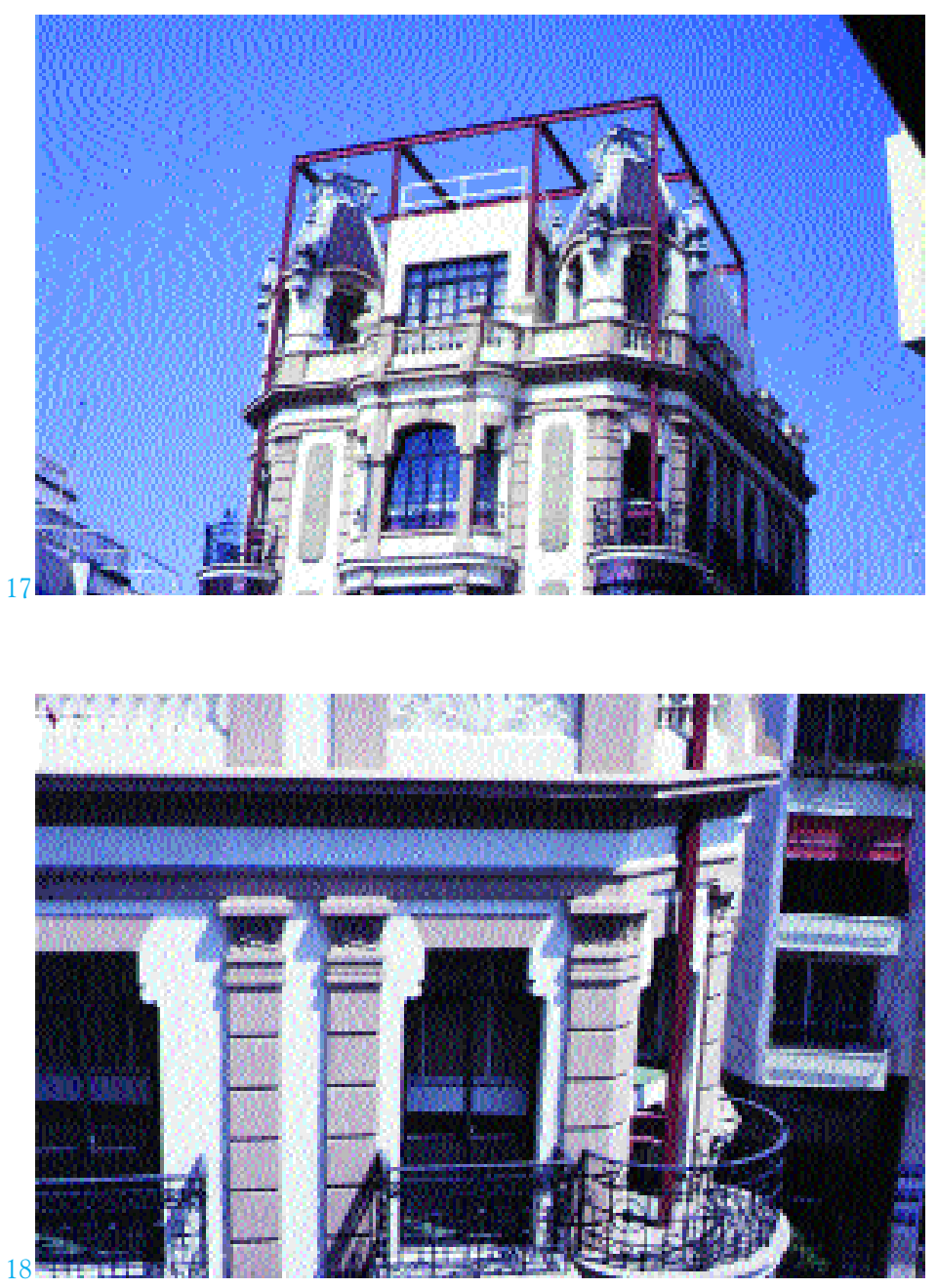